\title{
Mobile sexual health services for adolescents: investigating the acceptability of youth-directed mobile clinic services in Cape Town, South Africa
}

\author{
Philip Smith(1), Tsidiso Tolla, Rebecca Marcus and Linda-Gail Bekker
}

\begin{abstract}
Background: The Human Immunodeficiency Virus (HIV) epidemic is growing rapidly among South African adolescents and young adults (AYA). Although HIV counselling and testing, HIV prevention and treatment options are widely available, many AYA delay health-seeking until illness occurs, demonstrating a need for youth responsive, integrated sexual and reproductive health services (SRHS). While feasibility and cost-effectiveness have been evaluated, acceptability of mobile clinics among AYA has yet to be established. The objective of this study was to investigate patient acceptability of mobile AYA SRHS and compare mobile clinic usage and HIV outcomes with nearby conventional clinics.

Methods: Patients presenting to a mobile clinic in Cape Town were invited to participate in an acceptability study of a mobile clinic after using the service. A trained researcher administered an acceptability questionnaire. Mobile clinic medical records during the study period were compared with the records of AYA attending four clinics in the same community.

Results: Three hundred three enrolled participants (16-24 years, 246 (81.2\%) female) rated mobile AYA SRHS acceptability highly (median $=4,6$ out of 5), with $90 \%$ rating their experience as better or much better than conventional clinics. The mobile clinic, compared to conventional clinics, attracted more men $(26 \% \vee 13 \%, p<0$, 000), younger patients ( $18 \vee 19$ years, $p<0,000$ ), and yielded more HIV diagnoses $(4 \% \vee 2 \%, p<0,000)$.

Conclusions: Given the high ratings of acceptability, and the preference for mobile clinics over conventional primary health clinics, the scalability of mobile clinics should be investigated as part of a multipronged approach to improve the uptake of SRHS diagnostic, prevention and treatment options for AYA.
\end{abstract}

Keywords: Acceptability, Mobile clinic, Epidemiology, Usability, HIV, Differentiated healthcare

\section{Background}

Adolescents and young adults (AYA, 10-24 years) commonly express a desire to find out more about sex and sexual health, but tend to avoid sexual and reproductive health services (SRHS) because they experience real and perceived access barriers [1-6] . Barriers regularly cited involve anticipation of embarrassment, fear of loss of privacy, and fear of physical examination [6]. Although

\footnotetext{
* Correspondence: Philip.Smith@hiv-research.org.za

The Desmond Tutu HIV Centre, Institute for Infectious Disease and Molecular Medicine, Faculty of Health Science, University of Cape Town, Anzio Road, Observatory, Cape Town 7925, South Africa
}

some AYA may visit pharmacies and general practitioners, these alternative services may be out of reach because they are practically inaccessible due to cost, far traveling distance or the long time required for visits [7]. Many young South Africans only enter healthcare once ill and in need of care $[6,8,9]$.

The unique psychosocial and biological transitions place AYA in high disease burden communities at significant risk of human immunodeficiency virus (HIV) acquisition $[1,8,10,11]$. Sexual debut [12, 13] and developing sexuality both occur during this developmental phase and frequently co-occur with

(C) The Author(s). 2019 Open Access This article is distributed under the terms of the Creative Commons Attribution 4.0 International License (http://creativecommons.org/licenses/by/4.0/), which permits unrestricted use, distribution, and reproduction in any medium, provided you give appropriate credit to the original author(s) and the source, provide a link to the Creative Commons license, and indicate if changes were made. The Creative Commons Public Domain Dedication waiver (http://creativecommons.org/publicdomain/zero/1.0/) applies to the data made available in this article, unless otherwise stated. 
sexually transmitted infections (STIs) [3, 7, 14] and unintended pregnancies [15-17]. While HIV incidence and related mortality have declined in recent years [18], South African AYA have not experienced the same declines [3, 19-21].

Despite the recommendation to improve HIV testing in key populations [22], many AYA living with HIV remain unidentified until symptomatic $[9,23-25]$. The global scale-up of antiretroviral treatment (ART) has dramatically improved the quality of life for many people living with HIV. In combination with biochemical prevention methods, such as pre-exposure prophylaxis (PrEP), access to ART programs can significantly curb the HIV epidemic. Attaining this ambitious goal requires innovation that links young South Africans to SRHS, including diagnosis, prevention, treatment, adherence and viral suppression [1, 26-29]. With this in mind, youthfriendly services have been recommended for AYA [6, 30-32]. Youth-friendly services typically have been specifically designed for youth, or are conventional health facilities that have been adapted to serve AYA by providing tailored information and care that is appropriate to the developmental stage [34].

Adolescent responsive mobile clinics that offer integrated health services could ideally link potential patients to conventional clinics, and thus achieve more timeous risk reduction and treatment initiation [33, 34]. Although considered feasible and cost-effective for providing diagnostics to those at-risk of HIV acquisition in difficult to reach areas [24,35-37], user acceptability of these services for AYA has yet to be evaluated.

The primary objective of this study was to evaluate the acceptability of an AYA friendly mobile SRHS that encourages health-seeking in high disease burden settings in Cape Town, South Africa. The secondary objective was to compare AYA usage and HIV outcomes at the mobile clinic versus that among AYA attending four conventional primary healthcare clinics that operate in the same health district over a similar period.

\section{Methods}

\section{Study setting and participants}

The study was conducted in the Klipfontein Health Substructure, a high disease burden, resource limited, densely populated area in the Cape Town Metropolitan, South Africa. The mobile clinic, known as the Tutu Teen Truck, is implemented by the Desmond Tutu HIV Foundation, a non-governmental organisation providing HIV related services and conducting HIV and health related research in Cape Town, South Africa. The mobile clinic provided an adolescent and youth-friendly wellness service where AYA (12-24 years) could access screening for HIV, STIs, tuberculosis (TB), high blood pressure, diabetes mellitus, obesity and pregnancy.
From December 2016 to April 2017, AYA between 16 and 24 years old visiting the Tutu Teen Truck were recruited to participate in an acceptability study through purposive, convenient sampling. The mobile clinic parked in high traffic locations, such as commuter hubs and shopping centres, and offered free screening and testing. These locations were chosen in partnership with community representatives. Additionally, clinic records at the mobile clinic and four conventional clinics were reviewed to compare the characteristics of AYA 12-24 years. The research was approved by the Institutional Review Board (IRB) at the University of Cape Town (HREC Ref 141/2016). In consultation with the UCT IRB, a waiver of parental consent was obtained for the study on the grounds that adolescents access these services without need for parental consent, and the act of obtaining parental consent for the research could create a barrier to participation and undermine the acceptability objective.

\section{Procedure}

Participants that self-presented at the clinic were greeted by a staff member, who recorded their demographic information electronically on a tablet device and linked this information to the participant's fingerprint on biometric software. After registration, a trained healthcare worker screened and tested participants for HIV, pregnancy, hypertension, diabetes, and obesity using pointof-care diagnostics. Participants were also screened for symptoms of STIs and TB. Participants were not required to have all tests done although the whole spectrum was offered to all where appropriate, and pregnancy checks were offered to women. After completing $\mathrm{HCT}$, participants were invited to join the study. Written consent was obtained from all participants prior to completing the researcher administered questionnaire, which recorded demographics, acceptability of the clinic, and HIV risk perception. In addition, permission was obtained from the Cape Town Department of Health to review clinic records for four conventional government clinics in the same location during the period in which the study ran. Clinics were chosen based on proximity to the area in which the mobile clinic operated.

\section{Design}

This was a cross-sectional acceptability study which compared usage statistics of a mobile clinic versus conventional clinic facilities in the same district. Since no pre-existing acceptability instrument could be obtained, an 11-item scale was developed, which was derived from common desirable aspects of acceptable healthcare services [6]. Participants were asked to rate the 11 aspects of the mobile clinic service by answering Likert-type scale questions with ratings that ranged from 1 to 5 . A score of 5 indicated greater acceptability for all items in 
the scale except for a question that asked whether participants feared being seen at the clinic, which was reverse scored. The sum of the individual scale items (Table 2, Additional file 1) was used to generate an acceptability score. Participants were also asked to rate on a Likert-type scale their risk of three chronic diseases, including diabetes, hypertension and HIV. All analyses were conducted using Stata 14.0 (Stata Corporation LP, College Station, TX). Results were analysed for significant associations with sample demographics. Sample characteristics included age, gender, marital status, education, employment status, whether participants had ever tested, type of dwelling and HIV status. After calculating the proportions of HIV testing diagnoses at the mobile clinic and the conventional clinics, significant differences in proportions were analysed. Bivariate regression analyses were used to identify statistically significant associations and all significant associations $(p=0,05)$ were included in the multivariate regression model. Associations that retained significance were retained in the model.

\section{Results}

A total sample of 303 (19\% male) mostly Xhosa speaking (93\%) participants between the ages of 16 and 24 years (mean age 19,7) were retained in the analysis (Table 1). Most participants were unemployed (86\%) and did not earn an income (83\%). Half ( $n=150,50 \%)$ of the participants lived in informal housing and most (93\%) had previously tested for HIV.

When asked if they had used healthcare services in the past, most participants reported that they had used hospital services (47\%), followed by clinics (31\%) and mobile clinics (22\%). No adverse experiences were reported on the mobile clinic.

Since this was a newly created instrument for measuring acceptability, a Cronbach's alpha test of reliability was conducted and indicated acceptable internal consistency $(\alpha=0$, 77). All surveyed participants were either happy, or very happy with the duration of the mobile clinic visit (Table 2). Almost all participants $(99 \%, n=301)$ stated that the mobile clinic staff were friendly or very friendly. When asked if they would tell others about the mobile clinic service, nearly all $(99 \%, n=302)$ stated that they would. Most participants $(96 \%, n=290)$ stated that they believed the service was confidential and $(92 \%, n=279)$ were not concerned that someone they knew would see them at the service. All except one $(99 \%, \mathrm{n}=302)$ stated they would reuse the service. Most participants $(90 \%, n=273)$ stated that the mobile service was better or much better than conventional services, while a minority $(10 \%, n=29)$ stated that services at mobiles and conventional clinics were the same. A single participant $(0.3 \%)$ stated that conventional clinic services were better or much better. The length of time it took to be seen at a conventional clinic facility was the most often cited (47\%,
Table 1 Participant demographics and bivariate regressions for acceptability of the mobile clinic

\begin{tabular}{|c|c|c|c|}
\hline & n (\%) & mean $^{a}$ & $p^{b}$ \\
\hline Total & $303(100)$ & 4.6 & \\
\hline Age $(m=19,7)$ & $303(100)$ & & 0.394 \\
\hline Sex & & & 0.341 \\
\hline Female & $246(81.2)$ & 4.6 & \\
\hline Male & $57(18.8)$ & 4.6 & \\
\hline Employment & & & 0.147 \\
\hline Unemployed & $259(85.5)$ & 4.6 & \\
\hline Employed & $44(14.5)$ & 4.5 & \\
\hline Income & & & $0.014^{* *}$ \\
\hline Income & $53(17.5)$ & 4.5 & \\
\hline No Income & $250(82.5)$ & 4.6 & \\
\hline Education & & & $0.007^{* *}$ \\
\hline Primary School & $3(1)$ & 4.4 & \\
\hline High School & $230(75.9)$ & 4.6 & \\
\hline College/ University & $70(23.1)$ & 4.7 & \\
\hline Dwelling type & & & 0.590 \\
\hline Formal housing & $153(50.5)$ & 4.6 & \\
\hline Informal housing & $150(49.5)$ & 4.6 & \\
\hline Marital Status & & & 0.515 \\
\hline Single & $287(94.7)$ & 4.6 & \\
\hline Cohabiting & $13(4.3)$ & 4.7 & \\
\hline Married & $3(1)$ & 4.6 & \\
\hline Ever Tested & & & $0.001^{* *}$ \\
\hline Never Tested & $22(7.3)$ & 4.4 & \\
\hline Tested Before & $281(92.7)$ & 4.6 & \\
\hline HIV Status & & & 0.345 \\
\hline HIV positive (new diagnosis) & $8(3.3)$ & 4.7 & \\
\hline HIV negative & $232(96.7)$ & 4.6 & \\
\hline
\end{tabular}

$n=143)$ barrier to accessing healthcare, followed by unfriendly staff $(31 \%, n=93)$ and distance $(22 \%, n=67)$. When asked to rate their risk of diabetes, hypertension and HIV infection on a Likert-type scale, 65, 67 and 76\% of participants stated that they were not at risk of these conditions respectively. A Wilcoxon signed-rank test showed that risk for HIV was rated significantly lower than either risk for diabetes $(Z=-2.898, p=0.004)$ or hypertension $(\mathrm{Z}=-3.165, p=0.002)$.

In the multivariate analysis (Table 3 ), higher income $(p=0.004, \mathrm{CI}-.266-.052)$, higher education $(p=0.003$, CI .022 .108) and having been previously tested for HIV ( $p=0.008$, CI .053 .360) remained associated with higher acceptability scores, but there was low predictive value for the effect on acceptability ( $\mathrm{R}$-squared $=0.079$ ). 
Table 2 Acceptability ratings of the mobile clinic

\begin{tabular}{|c|c|c|c|c|c|c|c|c|c|c|c|c|c|}
\hline \multirow{2}{*}{$\begin{array}{l}\text { Acceptability ( } 1=\text { poor rating, } 5=\text { high rating except where indicated } \\
\text { otherwise) }\end{array}$} & \multirow[t]{2}{*}{$\mathrm{n}$} & \multirow[t]{2}{*}{ Mdn } & \multirow[t]{2}{*}{$(\mathrm{IQR})$} & \multicolumn{2}{|l|}{1} & \multicolumn{2}{|l|}{2} & \multicolumn{2}{|l|}{3} & \multicolumn{2}{|l|}{4} & \multicolumn{2}{|l|}{5} \\
\hline & & & & n & $\%$ & n & $\%$ & $\mathrm{n}$ & $\%$ & $\bar{n}$ & $\%$ & $\bar{n}$ & $\%$ \\
\hline 1. How easy was it to understand the counselling at the mobile clinic? & 303 & 4.00 & $\begin{array}{l}(4- \\
5)\end{array}$ & 0 & $0 \%$ & 1 & $0 \%$ & 0 & $0 \%$ & 166 & $55 \%$ & 136 & $45 \%$ \\
\hline 2. Please rate how helpful was the mobile clinic service? & 303 & 5.00 & $\begin{array}{l}(4- \\
5)\end{array}$ & 0 & $0 \%$ & 0 & $0 \%$ & 1 & $0 \%$ & 138 & $46 \%$ & 164 & $54 \%$ \\
\hline 3. Would you consider using the mobile clinic service again? & 303 & 5.00 & $\begin{array}{l}(4- \\
5)\end{array}$ & 1 & $0 \%$ & 0 & $0 \%$ & 0 & $0 \%$ & 113 & $37 \%$ & 189 & $62 \%$ \\
\hline 4. How likely are you to tell others about the mobile clinic service? & 303 & 5.00 & $\begin{array}{l}(5- \\
5)\end{array}$ & 1 & $0 \%$ & 0 & $0 \%$ & 0 & $0 \%$ & 2 & $1 \%$ & 300 & $99 \%$ \\
\hline 5. How happy were you with the time it took to be seen at the mobile clinic? & 303 & 5.00 & $\begin{array}{l}(4- \\
5)\end{array}$ & 0 & $0 \%$ & 0 & $0 \%$ & 0 & $0 \%$ & 95 & $31 \%$ & 208 & $69 \%$ \\
\hline 6. Please rate how friendly was the clinic service? & 303 & 5.00 & $\begin{array}{l}(5- \\
5)\end{array}$ & 0 & $0 \%$ & 2 & $1 \%$ & 0 & $0 \%$ & 68 & $22 \%$ & 233 & $77 \%$ \\
\hline 7. How do mobile clinics compare with traditional clinics/ hospitals? & 303 & 5.00 & $\begin{array}{l}(4- \\
5)\end{array}$ & 0 & $0 \%$ & 1 & $0 \%$ & 29 & $10 \%$ & 81 & $27 \%$ & 192 & $63 \%$ \\
\hline 8. How do mobile clinics staff compare with traditional clinics/ hospitals? & 303 & 5.00 & $\begin{array}{l}(4- \\
5)\end{array}$ & 0 & $0 \%$ & 1 & $0 \%$ & 27 & $9 \%$ & 76 & $25 \%$ & 199 & $66 \%$ \\
\hline $\begin{array}{l}\text { 9. How concerned are you that someone may see you at the mobile clinic? } \\
\text { (reverse scored) }\end{array}$ & 303 & 5.00 & $\begin{array}{l}(5- \\
5)\end{array}$ & 1 & $0 \%$ & 19 & $6 \%$ & 4 & $1 \%$ & 13 & $4 \%$ & 266 & $88 \%$ \\
\hline $\begin{array}{l}\text { 10. Compared with traditional clinics, mobile clinics are } 1=\text { much worse, } 5= \\
\text { much better }\end{array}$ & 303 & 5.00 & $\begin{array}{l}(4- \\
5)\end{array}$ & 11 & $4 \%$ & 29 & $10 \%$ & 30 & $10 \%$ & 64 & $21 \%$ & 169 & $56 \%$ \\
\hline 11. Overall, how would you rate your experience at the mobile clinic? & 303 & 5.00 & $\begin{array}{l}(4- \\
5)\end{array}$ & 0 & $0 \%$ & 0 & $0 \%$ & 14 & $5 \%$ & 119 & $39 \%$ & 170 & $56 \%$ \\
\hline
\end{tabular}

Because utilization of the mobile clinic was voluntary, the characteristics of the AYA who attended the Tutu Teen Truck was compared with all the AYA who attended the four nearest conventional clinic facilities in the area over the same period as a measure of usage. Between December 2016 and April 2017, 4887 patients (Table 4) between the ages of 12 and 25 visited SRHS at the clinic facilities (3737 visited the four conventional clinics, and 1150 visited the adolescent-friendly mobile clinic). The mean age for patients in this age group was 19,1 years (19,3 years at the conventional clinic, 18,4 years at the mobile clinic).

Sixteen percent $(16,3 \%)$ of patients were male, with the mobile clinic recording a higher proportion of males (26, $4 \%)$ than the conventional clinics (13,2\%). The overall HIV prevalence was $2,4 \%$, where prevalence was $2 \%$ at the conventional clinics, and $4 \%$ at the mobile clinic. The HIV prevalence in the $\geq 20$ year old age group was more than double that of the 17-19 year old group. The univariate analysis showed that patients who visited the mobile clinic

Table 3 Multivariate regression analysis model for factors impacting acceptability of the mobile clinic

\begin{tabular}{llllll}
\hline Usability R2 =0,079 & Estimate & $\mathrm{SE}$ & $\mathrm{t}$ & $\mathrm{p}$ & $95 \% \mathrm{Cl}$ \\
\hline Income & $-0,16$ & 0,054 & $-2,92$ & 0,004 & $(-0,27 ;-0,05)$ \\
Education & 0,06 & 0,022 & 2,98 & 0,003 & $(0,02 ; 0,11)$ \\
Ever tested & 0,21 & 0,078 & 2,65 & 0,008 & $(0,05 ; 0,36)$ \\
Constant co-efficient & 4,19 & 0,099 & 42,22 & 0,000 & $(4,00 ; 4,39)$ \\
\hline
\end{tabular}

differed significantly by age, sex, HIV result and pregnancy status. When HIV test result was disaggregated by age, males at the mobile were not more or less likely to be HIV positive, while females were more likely to test HIV positive at the mobile. At the mobile clinic a quarter (25,7\%) of patients reported that this was their first HIV tests (this data is not recorded in the conventional clinic records).

\section{Discussion}

Mobile services offer acceptable, accessible and cost-effective youth tailored services and can provide a gateway into HIV prevention and treatment for adolescents [1]. The results here echo other studies indicating widespread acceptability and uptake of mobile health services in underserved populations $[37,38]$. Acceptability was universally high in the sample, with the mobile clinic being perceived as efficient, confidential, friendly, easy to access, with information that was easy to understand. Even though almost all (96\%) participants rated the mobile service as confidential, a small number (7\%) were concerned that they might be seen at the clinic. Confidentiality and privacy are high priorities and it was exceptional that such a visible clinic was perceived to be confidential and private and that all participants except one were likely or very likely to tell others about the mobile. Such a finding is counterintuitive, but indicates that participants were comfortable accessing the mobile clinic in public spaces. 
Table 4 Comparison of clinic type by age, gender, HIV result and pregnancy result

\begin{tabular}{|c|c|c|c|c|c|c|c|}
\hline & \multicolumn{2}{|l|}{ Total } & \multicolumn{2}{|c|}{ Conventional } & \multicolumn{2}{|c|}{ Mobile } & \multirow[t]{2}{*}{$p$} \\
\hline & $\bar{n}$ & $\%$ & $\bar{n}$ & $\%$ & $\bar{n}$ & $\%$ & \\
\hline Overall & 4887 & 100 & 3737 & 76,5 & 1150 & 23,5 & \\
\hline Age & & & & & & & $0,000^{* *}$ \\
\hline Mean & 19,1 & & 19,3 & & 18,4 & & \\
\hline Median & 19 & & 19 & & 17,9 & & \\
\hline $12-14$ & 507 & 10,4 & 341 & 9,1 & 166 & 14,4 & \\
\hline $15-16$ & 680 & 13,9 & 439 & 11,8 & 241 & 21 & \\
\hline $17-19$ & 991 & 20,3 & 699 & 18,7 & 292 & 25,4 & \\
\hline $20-25$ & 2709 & 55,4 & 2258 & 60,4 & 451 & 39,2 & \\
\hline Sex & & & & & & & $0,000^{* *}$ \\
\hline Female & 4090 & 83,7 & 3244 & 86,8 & 846 & 73,6 & \\
\hline $12-14$ & 397 & 9,7 & 289 & 8,9 & 108 & 12,8 & \\
\hline $15-16$ & 597 & 14,6 & 414 & 12,8 & 183 & 21,6 & \\
\hline $17-19$ & 862 & 21,1 & 645 & 19,9 & 217 & 25,7 & \\
\hline $20-25$ & 2234 & 54,6 & 1896 & 58,4 & 338 & 40 & \\
\hline Male & 797 & 16,3 & 493 & 13,2 & 304 & 26,4 & \\
\hline $12-14$ & 110 & 13,8 & 52 & 10,5 & 58 & 19,1 & \\
\hline $15-16$ & 83 & 10,4 & 25 & 5,1 & 58 & 19,1 & \\
\hline $17-19$ & 129 & 16,2 & 54 & 11 & 75 & 24,7 & \\
\hline $20-25$ & 475 & 59,6 & 362 & 73,4 & 113 & 37,2 & \\
\hline HIV test result & & & & & & & $0,000^{* *}$ \\
\hline $\mathrm{HIV+}$ & 119 & 2,4 & 73 & 2 & 46 & 4 & \\
\hline $12-14$ & 1 & 0,2 & 1 & 0,3 & 0 & 0 & \\
\hline $15-16$ & 6 & 0,9 & 1 & 0,2 & 5 & 2,1 & \\
\hline $17-19$ & 16 & 1,6 & 6 & 0,9 & 10 & 3,4 & \\
\hline $20-25$ & 96 & 3,5 & 65 & 2,9 & 31 & 6,9 & \\
\hline Female HIV+ & 103 & 2,5 & 64 & 2 & 39 & 4,6 & $0,000^{* *}$ \\
\hline $12-14$ & 1 & 0,3 & 1 & 0,3 & 0 & 0 & \\
\hline $15-16$ & 5 & 0,8 & 1 & 0,2 & 4 & 2,2 & \\
\hline $17-19$ & 14 & 1,6 & 5 & 0,8 & 9 & 4,1 & \\
\hline $20-25$ & 83 & 3,7 & 57 & 3 & 26 & 7,7 & \\
\hline Male HIV+ & 16 & 2 & 9 & 1,8 & 7 & 2,3 & 0,642 \\
\hline $12-14$ & 0 & 0 & 0 & 0 & 0 & 0 & \\
\hline $15-16$ & 1 & 1,2 & 0 & 0 & 1 & 1,7 & \\
\hline $17-19$ & 2 & 1,6 & 1 & 1,9 & 1 & 1,3 & \\
\hline $20-25$ & 13 & 2,7 & 8 & 2,2 & 5 & 4,4 & \\
\hline Pregnancy tests & 654 & & 496 & & 158 & & $0,000^{* *}$ \\
\hline Pregnant & 167 & 25,5 & 156 & 31,5 & 11 & 7 & \\
\hline
\end{tabular}

When the data from the two clinic types were compared, the results showed that the mean age was lower for those accessing the mobile clinic and that the mobile attracted a higher proportion of young men than the conventional clinics. This is an encouraging finding since men generally access conventional facilities at lower rates and are less likely to test and know their status than women. Consequently, mobile clinics may provide opportunities for prevention and treatment to reduce morbidity and mortality amongst young men. Moreover, the mobile clinic found a higher yield of HIV positive young people than the conventional clinics. When disaggregated by sex, HIV prevalence remained significantly higher for women visiting the mobile clinic versus the conventional clinic, but not for men. This may be due to the national trend for a delayed upswing in HIV prevalence for men when compared with women [39]. The pregnancy rates between the two facility types also differed significantly where more young women tested positive for pregnancy at the conventional facilities. This may be an indication that mobiles could be effective sites for implementing convenient family planning counselling and for dispensing contraceptive methods for young people.

It was significant that previously tested participants gave higher ratings of the mobile clinic service. Qualitative data from a study with South African AYA, which investigated young people's preferences for desirable healthcare services, showed that trust between young people and healthcare providers is vital in supporting youth engagement in care [40]. It may be that those who had previously tested had a comparator and had subsequently formed good impressions of the professional-patient relationships with health providers on the mobile service, and as a result rated the service more highly. Even though debut testers gave lower ratings than repeat testers, their ratings were still high.

Overall, these results resonate with findings from elsewhere in South Africa showing that mobile clinics are an effective strategy for overcoming the barriers to reaching young people, and as an added benefit, are effective at reaching young men who access conventional clinics at lower rates than women [38]. The need for continued awareness raising, community-based efforts for HIV testing and casefinding of young people living with HIV is supported by the finding that participants were more likely to deny vulnerability to HIV than other chronic conditions.

Self-selection for the service and the study was a limitation that may have influenced the high levels of acceptability. Even though the mobile service strategically selected high disease burden communities, patients who know they are high risk, or who presume an HIV positive diagnosis, may avoid diagnostic services because of anticipated stigma or self-stigmatisation around an HIV positive result, denial, or a desire to delay knowing the result. Fine-grained geospatial mapping may help to target areas as specific as streets and blocks to improve the yield of those who are most at risk. Further to this limitation is that questionnaires were researcher-led, and therefore possibly subject to social desirability bias. One way to control for this may be to use computer-assisted or tablet- 
based self-administered surveys, or community-based surveys away from clinic settings to minimise this bias. Even so, while self-selection may have positively skewed acceptability, the comparison with the conventional clinics showed that the mobile clinic saw proportionately more HIV positive patients, indicating that mobile clinics may be more successful at finding new HIV infections.

The study did not record participation refusals and associated reasons for refusal. The majority $(68 \%)$ of those who completed the questionnaire were female, and therefore an equal spread of answers across the sexes was not established. However, even though young men only constituted $32 \%$ of those who completed the questionnaire, this figure was higher than the proportion of men who visited the mobile clinic during the course of the study (26\%). Since inception in 2015, men have constituted $40 \%$ of clinic visits at the mobile, which is encouraging. While the higher proportion of young men testing at the mobile may indicate that mobile testing is more desirable to men than testing at a conventional facility, the proportion of those HIV positive was not significantly different from the conventional clinic. Future research could investigate mobile clinics that incorporate young men's healthcare needs since dedicated men's clinics may be a more attractive option because they are tailored to men.

\section{Conclusions}

Mobile clinics can offer convenient and complimentary service to conventional clinics and the ability to actively target at-risk communities can provide earlier detection of HIV and provide relief to brick and mortar clinics. Additionally, mobile SRHS can make health-seeking more convenient for AYA. Examples of possible models for mobile units include diagnostic versus one-stop mobile clinics that provide a range of diagnostic, prevention and treatment services. Cost effectiveness of an integrated, one-stop diagnostic and prevention and treatment service should be determined, but may go some way towards addressing attrition between testing and treatment services [41]. Mobile clinics can target high risk communities and can provide convenient access to much needed SRHS. This delivery platform leans heavily into decreasing effort, decreasing time, improving the emotional experience, and ensuring easier uptake for at-risk AYA by strategically locating the service where it is needed.

This study demonstrated that mobile clinics are more desirable and can achieve high acceptability amongst young people in need of sexual and reproductive healthcare in a resource-limited, high disease burden setting in South Africa. The results further demonstrated that this mobile clinic offered convenience, trusting relationship and confidentiality. Accordingly, mobile clinics should be used as part of a multi-faceted approach to increase the convenience of HIV testing and counselling for adolescents and young adults in resource-limited settings. Future studies to evaluate acceptability of these services amongst those even harder to reach, including young men and boys and debut testers are warranted.

\section{Additional file}

Additional file 1 Acceptability questionnaire. (PDF 62 kb)

\section{Abbreviations}

ART: Antiretroviral treatment; AYA: Adolescent and young adult; HIV: Human immunodeficiency virus; PrEP: Pre-exposure prophylaxis; SRHS: Sexual and reproductive health services; STIs: Sexually transmitted infections;

TB: Tuberculosis

\section{Acknowledgements}

We thank the young South African participants and their families, for their willingness to volunteer and participate in the research. We also thank all the clinical teams and terrific study co-ordinators, who made the experience safe and friendly for the participants.

\section{Authors' contributions}

PS was lead investigator and lead author, conceptualised the study, designed the data analysis, was responsible for study execution, cleaned and merged all data, and conducted the data analysis. TT supported data collection, collated the data, collaborated in data analysis and critically reviewed the manuscript. RM collaborated in data analysis and critically reviewed the manuscript. L-GB was coinvestigator, supervised study design, and critically reviewed the manuscript. All authors have read and approved the manuscript.

\section{Funding}

The Tutu Teen Truck mobile clinic was funded by Abbott and Chevron South Africa. Philip Smith and Tsidiso Tolla were funded by the National Research Foundation. The funders played no role in the study design study, data collection, analysis, interpretation of data or writing the manuscript.

\section{Availability of data and materials}

The datasets used and/or analysed during the current study are available from the lead author on reasonable request.

\section{Ethics approval and consent to participate}

Ethical approval was obtained from the University of Cape Town's Human Research Ethics Committee (Reference: HREC 141/2016). Written informed consent to participate in the study was obtained from all participants. A waiver of parental consent was obtained for the survey on the grounds that South African adolescents 12 years and older access sexual health services without need for parental consent, and the act of obtaining parental consent for the research could create a barrier to participation and undermine the acceptability objective.

\section{Consent for publication}

Not applicable. This manuscript contains no identifiable data.

\section{Competing interests}

The authors declare that they have no competing interests.

Received: 10 April 2019 Accepted: 9 August 2019

Published online: 19 August 2019

References

1. Bekker L-G, Johnson L, Wallace M, Hosek S. Building our youth for the future. J Int AIDS Soc. 2015;18(2 Suppl 1):20027.

2. Black S, Wallace M, Middelkoop K, Robbertze D, Bennie T, Wood R, et al. Improving HIV testing amongst adolescents through an integrated Youth Centre rewards program: Insights from South Africa. Child Youth Serv Rev. 2014; Available from: http://www.sciencedirect.com/science/article/pii/S01 90740914001315. [cited 2014 Jun 4]. 
3. Geary RS, Gómez-Olivé FX, Kahn K, Tollman S, Norris SA. Barriers to and facilitators of the provision of a youth-friendly health services programme in rural South Africa. BMC Health Serv Res. 2014;14(1):259.

4. Geary RS, Webb EL, Clarke L, Norris SA. Evaluating youth-friendly health services: young people's perspectives from a simulated client study in urban South Africa. Glob Health Action. 2015;8(0). Available from: https://www. tandfonline.com/doi/full/10.3402/gha.v8.26080. [cited 2015 Jul 30]

5. Svanemyr J, Amin A, Robles OJ, Greene ME. Creating an enabling environment for adolescent sexual and reproductive health: a framework and promising approaches. J Adolesc Health. 2015;56(1, Supplement):S7-14.

6. James S, Pisa PT, Imrie J, Beery MP, Martin C, Skosana C, et al. Assessment of adolescent and youth friendly services in primary healthcare facilities in two provinces in South Africa. BMC Health Serv Res. 2018;18(1):809.

7. Strauss M, Rhodes B, George G. A qualitative analysis of the barriers and facilitators of HIV counselling and testing perceived by adolescents in South Africa. BMC Health Serv Res. 2015;15:250.

8. Dickson-Tetteh K, Pettifor A, Moleko W. Working with public sector clinics to provide adolescent-friendly services in South Africa. Reprod Health Matters. 2001;9(17):160-9.

9. Hosek S, Celum C, Wilson CM, Kapogiannis B, Delany-Moretlwe S, Bekker LG. Preventing HIV among adolescents with oral PrEP: observations and challenges in the United States and South Africa. J Int AIDS Soc. 2016; 19(7Suppl 6) Available from: http://www.ncbi.nlm.nih.gov/pmc/articles/ PMC5071778/. [cited 2017 Apr 3].

10. Wood K, Jewkes R. Blood blockages and scolding nurses: barriers to adolescent contraceptive use in South Africa. Reprod Health Matters. 2006;14(27):109-18.

11. Pettifor A, Bekker L-G, Hosek S, DiClemente R, Rosenberg M, Bull S, et al. Preventing HIV among Young People: research priorities for the future. J Acquir Immune Defic Syndr 1999. 2013;63(0 2):S155-60.

12. Victor EC, Hariri AR. A neuroscience perspective on sexual risk behavior in adolescence and emerging adulthood. Dev Psychopathol. 2016;28(2):471-87.

13. Simbayi LC, Chauveau J, Shisana O. Behavioural responses of south African youth to the HIV/AIDS epidemic: a nationwide survey. AIDS Care. 2004;16(5):605-18.

14. Zuma K, Setswe G, Ketye Y, Mzolo T, Rehle T, Mbelle N. Age at sexual debut: a determinant of multiple partnership among south African youth. Afr J Reprod Health. 2014;14(2):47-54.

15. Barnabas SL, Jaspan HB, Dabee S, Jaumdally SZ, Gamieldien H, Lewis D, et al. Knowing whom we are trying to protect: an assessment of HIV risk in south African adolescent females. AIDS Res Hum Retrovir. 2014;30(S1):A131.

16. Mkhwanazi N. A tough love approach indeed: Demonising early childbearing in the Zuma era. Agenda. 2012;26(4):73-84.

17. Christofides NJ, Jewkes RK, Dunkle KL, Nduna M, Shai NJ, Sterk C. Early adolescent pregnancy increases risk of incident HIV infection in the Eastern Cape, South Africa: a longitudinal study. J Int AIDS Soc. 2014;17(1) Available from: http://www. ncbi.n/m.nih.gov/pmc/articles/PMC3962027/. [cited 2015 Aug 19].

18. Macleod Cl, Tracey T. A decade later: follow-up review of south African research on the consequences of and contributory factors in teen-aged pregnancy. South Afr J Psychol. 2010;40(1):18-31.

19. Williams BG, Gupta S, Wollmers M, Granich R. Progress and prospects for the control of HIV and tuberculosis in South Africa: a dynamical modelling study. Lancet Public Health. 2017;2(5):e223-30.

20. Delany-Moretlwe S, Cowan FM, Busza J, Bolton-Moore C, Kelley K, Fairlie L. Providing comprehensive health services for young key populations: needs, barriers and gaps. J Int AIDS Soc. 2015;18(2Suppl 1) Available from: http:// www.ncbi.n/m.nih.gov/pmc/articles/PMC4344539/. [cited 2015 Aug 12].

21. Dellar RC, Dlamini S, Karim QA. Adolescent girls and young women: key populations for HV epidemic control. J Int AIDS Soc. 2015;18(2Suppl 1) Available from: http://www.ncbi.nlm.nih.gov/pmc/articles/PMC4344544/. [cited 2015 Aug 19].

22. Moodley N, Gray G, Bertram M. The case for adolescent HIV vaccination in South Africa: a cost-effectiveness analysis. Medicine (Baltimore). 2016;95(4):e2528

23. Shisana O, Rehle T, Simbayi L, Zuma K, Jooste S, Zungu N. South African national HIV prevalence, incidence and behaviour survey, 2012. Cape Town: HSRC Press; 2014.

24. Goldenberg JL, Arndt J, Hart J, Routledge C. Uncovering an existential barrier to breast self-exam behavior. J Exp Soc Psychol. 2008:44(2):260-74.

25. Govindasamy D, Ford N, Kranzer K. Risk factors, barriers and facilitators for linkage to antiretroviral therapy care: a systematic review. AIDS. 2012;26(16):2059-67.

26. Mulaudzi M, Dlamini BN, Coetzee J, Sikkema K, Gray G, Dietrich Jנ. Perceptions of counsellors and youth-serving professionals about sexual and reproductive health services for adolescents in Soweto, South Africa. Reprod Health. 2018;15(1):21.
27. Bastani P, Hogg RS, Marshall B, Montaner JSG, Ramadanovic B, Rutherford AR, et al. Highly active antiretroviral therapy eliminates HIV epidemics in a ! Network model of an injecting drug user community! Group; 2010. p. 2010.

28. Pop-Eleches C, Thirumurthy H, Habyarimana JP, Zivin JG, Goldstein MP, de Walque D, et al. Mobile phone technologies improve adherence to antiretroviral treatment in a resource-limited setting: a randomized controlled trial of text message reminders. AIDS Lond Engl. 2011;25(6):825-34.

29. Velasco-Hernandez JX, Gershengorn HB, Blower SM. Could widespread use of combination antiretroviral therapy eradicate HIV epidemics? Lancet Infect Dis. 2002;2(8):487-93.

30. Zanoni BC, Archary M, Buchan S, Katz IT, Haberer JE. Systematic review and meta-analysis of the adolescent HIV continuum of care in South Africa: the cresting wave. BMJ Glob Health. 2016;1(3):e000004.

31. Dickson KE, Ashton J, Smith J-M. Does setting adolescent-friendly standards improve the quality of care in clinics? Evidence from South Africa. Int J Qual Health Care. 2007;19(2):80-9.

32. WHO. Making health services adolescent friendly: Developing national quality standards for adolescent friendly health services. 2012;

33. Tylee A, Haller DM, Graham T, Churchill R, Sanci LA. Youth-friendly primarycare services: how are we doing and what more needs to be done? Lancet. 2007;369(9572):1565-73.

34. Govindasamy D, Ferrand RA, Wilmore SM, Ford N, Ahmed S, Afnan-Holmes $\mathrm{H}$, et al. Uptake and yield of HIV testing and counselling among children and adolescents in sub-Saharan Africa: a systematic review. J Int AIDS Soc. 2015;18(1). Available from: https://www.ncbi.nlm.nih.gov/pubmed/26471265. [cited 2015 Oct 15].

35. van Schaik N, Kranzer K, Wood R, Bekker L-G. Earlier HIV diagnosis--are mobile services the answer? South Afr Med J Suid-Afr Tydskr Vir Geneeskd. 2010;100(10):671-4.

36. Bassett IV, Govindasamy D, Erlwanger A, van Schaik N, Noubary F, Wood R, et al. Mobile HIV screening very cost effective in South Africa. PharmacoEconomics Outcomes News. 2013;676(1):10.

37. Maheswaran $H$, Thulare $H$, Stanistreet D, Tanser F, Newell M-L. Starting a home and mobile HIV testing service in a rural area of South Africa. J Acquir Immune Defic Syndr 1999. 2012;59(3):e43-6.

38. Sharma M, Ying R, Tarr G, Barnabas R. Systematic review and meta-analysis of community and facility-based HIV testing to address linkage to care gaps in sub-Saharan Africa. Nature. 2015;528(7580):S77-85.

39. van Rooyen H, McGrath N, Chirowodza A, Joseph P, Fiamma A, Gray G, et al. Mobile VCT: reaching men and young people in urban and rural south African pilot studies (NIMH project accept, HPTN 043). AIDS Behav. 2013; 17(9):2946-53.

40. HSRC. The fifth south African national HIV prevalence, incidence, behaviour and communication survey, 2017: HIV impact assessment summary report. 2018. Available from: http://www.hsrc.ac.za/uploads/pageContent/9234/ SABSSMV_Impact_Assessment_Summary_ZA_ADS_cleared_PDFA4.pdf. [cited 2018 Sep 13].

41. Smith $P$, Marcus $R$, Bennie $T$, Nkala B, Nchabeleng M, Latka MH, et al. What do south African adolescents want in a sexual health service? Evidence from the south African studies on HIV in adolescents (SASHA) project. S Afr Med J. 2018;108(8):677-81.

\section{Publisher's Note}

Springer Nature remains neutral with regard to jurisdictional claims in published maps and institutional affiliations.

\section{Ready to submit your research? Choose BMC and benefit from:}

- fast, convenient online submission

- thorough peer review by experienced researchers in your field

- rapid publication on acceptance

- support for research data, including large and complex data types

- gold Open Access which fosters wider collaboration and increased citations

- maximum visibility for your research: over $100 \mathrm{M}$ website views per year

At BMC, research is always in progress.

Learn more biomedcentral.com/submissions 